AÜIFD Cilt XLIV (2003) Sayt 2 s. 337-346

\title{
Sistematik Teolog İçin Dinler Tarihinin Önemi*
}

\section{Paul TILLICH / Çev.: Aliye ÇINAR}

Ar. Gör., Uludağ Üniversitesi İlâhiyat Fakültesi,

Bu konferansta üç temel mütalaaya temas etmek istiyorum. İlkine "iki esas karar" diyeceğim. "Sistematik Teolog için Dinler Tarihinin Önemi" konusunu kabul eden ve bu konuyu ciddî olarak ele alan bir teolog zaten açıkça ya da zımnen, iki temel karar vermiş demektir. Bir yandan, o kendini teoloğu olduğu dinlerin dışındaki bütün dinleri reddeden bir teolojiden ayırmıştır. Öte yandan da eğer konu olumlu ve ciddî olarak kabul edilirse, 0 ,

\footnotetext{
- Çevirisini sunduğumuz bu yazı, hem Tillich'e şükran yazıları olarak başkalarınca kaleme alınan, hem de bizzat Tillich'in makalelerinden müteşekkil olan, Hannah Tillich tarafından derlenen, The Future of Religions isimli kitabin 80-94. Sayfalarinda yer alan The Significance of the History of Religions for the Systematic Theologian başlıklı bir konferans metnidir (1966, U.S.A., Harper Row).
} 
din olmayan bir din paradoksunu, seküler teoloji de denilen tanrısız bir teolojiyi reddetmiştir.

Her iki tutumun da uzun bir tarihi vardır. İlki, yüzỵılımızın teoloğu Karl Barth tarafından yenilenmiştir. İkincisi şimdilerde tavizsiz bir şekilde "Tanrı'sız teoloji" diliyle ifade edilmektedir. Önceki tutum için ya bir din bütün diğer sahte dinlere (religiones falsâe) karşı hakiki din (vera religio) olur ya da modern terimlerle ifade edilirse, birinin kendi dinî vahiydir ancak diğer din, Tanrı'ya ulaşmak için nâfile insanî bir teşebbüstür. Bu, bütün dinin tanımı olur -Tanrıya ulaşmak için beyhude bir insanî teşebbüstür.

Dolayısıyla bu perspektiften bakıldığında, dinlerin somut farklarına derinlemesine girmek gerekli değildir. Örneğin bunu çok katı olmamakla birlikte Emil Brunner'in yaptığını hatırlıyorum. Pek saygıdeğer arkadaşım merhum Rudolf Otto ve hatta bugün benzer durumdaki bir kişi olan Friedrich Heiler gibi din tarihçilerinin teolojik tecridini anımsıyorum. Ayrıca Hristiyanlık için kendi din kavramını kullanmasından dolayı Schleirmacher'e karşı yapıllan ağır hücum akla gelebilir. Marburg'da Schleirmacher üzerine ilk kez (kırk yıl önce) bir seminer verdiğim zaman görüşlerime karşı çıkıldığırı hatırlıyorum. Böyle bir yaklaşım o zaman için suç olarak mütalaa edilirdj.

Bu şekildeki hem eski hem de yeni ortodoks tutumu reddetmek için aşağıdaki sistematik varsayımların kabul edilmesi gerekir. İlki, vahiy tecrübelerin evrensel olarak insanî olduğunun ifade edilmesi gerekir. Dinler, her nerede yaşarsa yaşasın insana verilen bir şeye dayanır. İnsana, her zaman kurtarıcı güçleri imâ eden özel bir tecrübe çeşidi yani vahiy verilir. Vahiy ve kurtuluş kesinlikle birbirinden ayrılamaz. Bütün dinlerde ilham verici ve kurtarıcı güçler vardır. Tanrı kendini tanıksız bırakmamıştır. Bu, ilk varsayımdir.

Íkinci varsayım: İnsan, vahyi kendi sonlu durumuyla alır. İnsan biyolojik, psikolojik ve s.osyolojik olarak sınırlıdır. Dolayısıyla vahiy, insanın kendine yabancılą̧ma şartları altında alınır. Özellikle din, bizatihi bir amaç olarak değil de jir amaca araç olarak kullanılırsa vahiy, daima tahrif edilmiş bir formda alınır.

Kabul edilmesi gereken üçüncü bir varsayım: Sistematik teologlar dinler tarihinin önemini kabul ettiği zaman, bu kabul, sadece insanlık tarihi boyunca varolan vahyî tecrübelere inancı değil, aynı zamanda intibak sınırlarında ve eleştiriye k.onu olan tahrif başarısızlıklarında da vahyî bir sürecin olduğu kanaatini it.tiva eder. Bu eleştiriler mistik, nebevî ve seküler olmak üzere üç form alır.

Dördüncü varsayım: Vahiy tecrübesinin içinde ve altında devam ettiği dinler tarihinde, böyle eleştirel gelişimlerin olumlu sonuçlarını birleştiren merkezî bir olay (event) olabilir (bu olabiliri vurguluyorum) -ki bu nedenle onun, evrensel öneme sahip somut bir teolojiyi mümkün kılan bir olay olmasi gerekir. 
Beşinci varsayım: Esas doğası içinde dinler tarihinin, kültür tarihiyle yan yana var olduğu söylenemez. Kutsal, sekülerin yanı başında uzanmış olmayıp bilakis, sekülerin derinliklerindedir. Kutsal yaratıcı temeldir ve aynı zamanda sekülerin eleştirel bir yargısıdır. Dinî olabilmesi için onun, aynı zamanda kişinin kendi dinî oto-kritiğinin bir aracı olarak seküleri kullanması gereken yani bizzat kendi üstüne dönen bir yargı olması gerekir.

$\mathrm{Bu}$ beş varsayımı kabul etmek isteyen bir teolog, yeni ve eski bir mutlakçılık adına böyle bir önemi reddedenlere karşı, teoloji için dinler tarihinin önemini ciddî ve tam olarak onaylar.

Öte yandan dinler tarihinin önemini kabul eden teolog, tanrisız teolojiye karşı durmalıdır. Ayrıca o, seküler ya da tâbir caizse tamamen seküler tarafından emilmiş olan kutsal fikri üstündeki özel vurguyu reddetmelidir.

Beş husustan sonuncusu, kutsal ile seküler ilişkisine dâir husus, zaten "Tanrı'nın ölü olduğu" şeklindeki kehanetin tehdidini azaltmıştı. Din, seküleri bizzat kendine karşı eleştirel bir araç olarak kullanmalıdır ancak kesin soru şu: Iyi de, niçin herhangi bir din(le işe başliyoruz)? Burada dinler, bir semboller, ritüeller ve kurumlar anlamındadır. Büyü ve astroloji sahasını ihmal eden seküler bir teolog aynı şekilde, bunları da ihmal edemez mi? Eğer o, Tanrı fikrini kullanmıyorsa, onu dinler tarihine büyük anlam atfetmeye sevk eden nedir?

Bu kanattaki hücuma karşı dini tasdik etmek için teoloğun temel bir varsayımı olmalıdır. Teolog, sezgi ve eylemin sembollerinin bir yapısı olarak dinin -bu, sosyal bir grup içindeki mitler ve ritüeller demektir- en seküler kültürde ve bütünüyle mitten arındırılan teolojide bile, sürekli bir gereksinim olduğunu kabul etmelidir. Ben dinin sürekli bir gereksinim olduğunu, tinin gerçek ve etkin olabilmek için cisimleşmeye ihtiyaç duyduğu olgusundan çıkarıyorum. Kutsal'ın, Nihaî'nin ve Söz'ün seküler bir saha içinde olduğunu ve bunu pek çok kez bizzat tecrübe ettiğimi söylemek kesinlikle isabetlidir. Ancak bir şeyin, bir şeyin içinde olduğunu söylemek için onun en azından, ötekinin dışında bir olasılığa sahip olması gerekir. Diğer deyişle neyin içinde ve içinde olanın ne olduğu ayırt edilmelidir. Sorun şu: Seküler bir teolojinin objesi olabilen sekülerden, salt sekülerin farkı nerede aranacaktir?

Şimdi aynı şeyi gâyet bildik yani popüler formdaki şekliyle ifade edelim. Reformcular, her günün Rabb'in günü olduğunu söyledikleri zaman haklıydılar ve bu nedenle onlar, yedinci günün kutsallığının değerini düşürdüler. Ancak bunu söylemek için sadece bir zamanlar değil ancak sekülerin bunaltıcı sıkletine karşı her zaman dengeleyici olarak Rabb'in bir gününün olmuş olması gerekir. Bu, Tanrı dilini zorunlu kılan şeydir; her ne kadar bu gelenek dışı olsa da. Bu, din tarihinin ciddî olarak onanmasını mümkün kilar.

$\mathrm{Bu}$ nedenle teologlar olarak, dinler tarihine özgür bir yaklaşımı engelleyen iki bariyeri delip geçmemiz gerekir: Bu bariyerlerden biri 
dışlayıcı-gelenekçilik (the orthodox-exclusive) öteki ise yadsıyıcı-sekülerlik. Halis "din" kavramı, sistematik teolog için hâlâ bir problemler seli oluşturur ve bu, bir ittifakı içeren --her ne kadar zit yandan gelse de- iki öncü mukavemetle arttırılır. Bu oldu ve hâlâ olagelmektedir.

Her iki taraf da indirgerneci ve her ikisi de Nasıralı İsa'nın şahsı dışında her şeyi Hristiyanlıktan çıkarmaya meyletti. Yeni-ortodoks grup bunu, İsa'yı, vahiy sözünün duyulabildiği yegane durum yaparak icra eder. Seküler grup ise aynı şeyi ona teolojik olarak uygun bir sekülerliğin temsilciliğini vererek ifâ eder. Ancak bu, İsa'nın tablosu ve mesajı bizzat ciddî olarak indirgenirse yapılabilir. İsa, özellikle toplumsal açıdan, ahlâkî bir çağrının cisimleşmesi ile sınırlanmalıdır ve o zaman bu, Mesih'in bütün mesajının terk edildiği yegane şeydir. Elbette bu durumda, din tarihine -hatta Yahudi ve Hristiyan din tarihine- artık ihtiyaç duyulmaz. Bu nedenle dinler tarihinin değerli, takdire şâyan ve önemli anlayışına sahip olmak için zıt kutupların -seküler olduğu kadar gelenekçi- İsa-odaklı ittifakına nüfuz edilmesi gerekir.

Şimdi de sıra benim ikinci mütalaama, yani bir dinler tarihi teolojisine geldi. Geleneksel dinler tarihi bakışı, Eski ve Yeni Ahid'de bu tarihe söylenilenle sınırlandı ve o, bu tarihin devamı olarak kilise tarihini içine alması için genişletildi. Diğer dinler nitelik bakımından birbirinden ayrılamaz. Onların hepsi orijinal bir vahiy türünün dalâlete düşmüş hâlleridir; ancak Hristiyan teolojisi için herhangi bir değere ilişkin özel vahiy tecrübesi istisna. Onlar pagan milletlerin dinleridir, fakat onlar vahiy ve kurtuluşun taşıyıcısı dȩ̧̧ildir. Gerçekten bu prensip tam olarak sonuçlandırılmadı. Yahudiler ve Hristiyanlar gâlip ve mağlup milletlerin dinlerinden etkilendiler ve geneilikle bu dinler, Yahudilik ve Hristiyanlığın büyük ölçüde nefesini kesti ve onların her ikisinde de ateşli reaksiyonlara yol açtı.

Bu nedenle, -eğer bu konferansın başlığını kabul edersek ("Sistematik Teolog için Dinler Tarihinin Önemi")- evrensel vahyin pozitif değerinin eleştirel bir teolojiyi dengelediği bir dinler tarihi teolojisi ihtiyaç duyduğumuz şeydir. Her ikisi de gereklidir. Söz konusu dinler tarihi teolojisi, sistematik teologlara, hem Hristiyanlığın özel karakterini hem de onun evrensel iddiası çerçevesinde hâlihazırdaki ânını ve kendi tarihsel yerimizin doğasını anlamaya yardım eder.

Kendi incelememin şekillendirici periyodunu ve ondan sonra da Kitab-1 Mukaddes ve kilisenin tarihsel incelemelerinde Dinler Tarihi Okulu denilen şeyi -Almanca'sı religionsģeschichtliche Sechule- hatırladı̆ğm zaman hâlâ minnettarım: Bu incelemeler gözlerimi açtı ve bana Kitab-1 Mukaddes geleneğinin Anadolu ve Akdeniz geleneklerine katılma derecelerini gösterdi. Yaratılı̧ hikayelerinde ya da Hellenistik varoluşçulukta ve İran eskatolojisinde -Eski ve yeni Ahid'in geç periyotlarında ortaya çıktığı gibievrensel, insanî motiflere dâir anlayışın özgürleştirici etkisini anımsıyorum. 
Bu bakış açısından Dinler tarihinin hepsi, Yeni Ahid'in İsa anlayışı ve onun çalışmasına çerçeve teşkil eden kurtarıcı şahıslar için semboller ürettiler. Bunlar cennetten taş gibi düşmedi ancak sonuç itibariyle -kairos'da yani doğru zaman'da, nâiliyet zamanında- Mesih olarak Ísa'nın ortaya çıkışını mümkün kılan uzun bir hazırlayıcı vahiy tarihi vardır. Bütün bunlar, Eski Ahid'deki dine, peygamberî hücumun ve Yeni Ahid'deki İsa'nın eşsiz gücünün biricikliğini incitmeksizin yapılır. Daha sonraları, benim kendi gelişmemde, çoğu diğer teologlarda olduğu gibi, Eski ve Yeni Ahid durumunu kuşatan her iki dinin önemi ve Kitab-1 Mukaddes tarihinden oldukça uzaklaşan dinlerin ehemmiyeti vuzuha kavuşturuldu.

Bir İsrail tarihi tcolojisiyle ve Hristiyan kilisesinin teolojisi karşılaştırıldığında ilk karşılaşılan sorun, kurtuluş tarihidir; ancak kurtuluş tarihi, tarih içindeki bir şeydir. $O$, büyük sembolik anlarda, Kilise tarihinde reform hususundaki çeşitli çabalar gibi, kairoi'de ifade edilir. Aynı şekilde, hiç kimse dinler tarihi ile kurtuluş tarihi ya da vahyi özdeşleştiremez fakat sembolik anlar araştırılabilir. Eğer dinler tarihi ciddi olarak alınırsa, genel dinler tarihinde kairoi'ler var mıdır? Böyle kairoi'leri bulmak için teşebbüsler yapıldı. Söz konusu teşebbüsler on sekizinci yüzyılın aydınlanmacılarında vardı. Bu teologlar açısından her şey, insanoğlunun olgun akla ulaşmış olduğu büyük an, büyük kairos için birer hazırlıktı. Bu akılda hâlâ dinî ögeler vardır:Tanrı, özgürlük ve ölümsüzlük. Kant bunu, Saf Aklın Sınırları İçinde Din (Religion within the Limits of Pure Reason) isimli meşhur kitabında geliştirdi.

Diğer teşebbüs bizi Hegel'in ünlü çabasına götüren romantik tarih anlayışıydı. Onun bakış açısında, terakkici bir din tarihi vardır Din, bütün gerçekliğin yapısını veren temel felsefî kategorilere göre terakki eder. Dolayısıyla Hristiyanlık, en yüksek ve son noktadır ve ona "ifşa olan din" denir; bununla birlikte bu Hristiyanlık, felsefî olarak mitten arındırılmıştır (demythologized). Böyle bir bakış Kantçı felsefe ve Yeni Ahid mesajının bir birleşimidir.

Hegel'in dinler tarihi yorumunda daha önceki bütün dinlere, İngilizce'ye sadece iki kelime ile çevrilen, "içeri almak" (take in) ve "çıkarmak" (removed) anlamına gelen diyalektik olarak aşma (aufgehoben) gözüyle bakılabilir. Bu nedenle dinler tarihinde geçmiş olan şey anlamını kaybetmiştir. O, sadece daha geç gelişmedeki bir ögedir. Bu örneğin Hegel için şu anlama gelir: Hint dinleri çoktan sona ermiştir ve çağdaş anlamlarını yitirmişlerdir. Onlar, tarihin daha önceki bir devresine aittir. Hegel'in bir dinler tarihi geliştirme teşebbüsü, yaklaşık otuz yıl önce Amerika'da oldukça etkin olan deneysel teoloji ile sonuçlandı. $O$, gelecekte, dinî karaktere ilişkin yeni tecrübeler açan, değişmeden kalma (remaining) fikrine dayanır. Bugün Toynbee gibi insanlar bu yöne işaret ettiler -belki de onlar, büyük dinlerin birliğine götüren dinî tecrübenin doğasını araştırdılar. Ne de olsa bunlar, böyle bir yapıyı, böyle bir yorumu araştıran post-Hristiyan bir çağdır. 
Ayrıca esas itibariyle Hıristiyan olan, evrensel, ilâhî odaklı bir bilincin gelişimini vurgulayan Teilhard de Chardin'den de bahsetmek gerekir. Hristiyanlık geleceğin bütiin tinsel ögelerini içine alır. Ben böyle bir teşebbüsten hoşnut değilim. Ayrıca şahsen bundan kendi hesabıma da memnun değilim: ancak kendi kendinize denemenizi teşvik etmek için bu teşebbüsü size devredeceğim; çünkü dinler tarihini ciddî olarak ele alan kişinin bunu yapması gerekir.

Benim yaklaşımım 'dinamik-tipolojik' yaklaşımdır. Çünkü biteviye devam eden terakkici bir gelişme yoktur, ancak kutsal tecrübe edilirse, orada her zaman kutsal tecrübesincleki ögeler mevcuttur. Bunlar bir dinde baskınsa, bu ögeler özel bir din tipi yaratır. Daha çok derinlemesine gitmek gerekir ancak ben sadece bu şekilde ortaya çıkan tecrübî bir şemadan bahsedeceğim. Evrensel dinî temel, sonlunun içindeki Kutsal tecrübesidir. Genel olarak sonlu ve sınırlı her şeyde, ya da şu veya bu mahdut şeyde, kutsal özel bir şekilde tezahür eder. Ben buna bütün dinlerin âyinsel temeli diyeceğim -Misterli niteliğine rağmen, görülebilen, duyulabilen ve temas edilebilen Kutsal, burada ve şimdidedir. Biz en yüksek dinlerin âyinlerinde bu kalıntılara şahit olabilmekteyiz. Tıpkı âyinsel temelini kaybetmiş olmasından dolayı Protestanlığın çoğunluğundaki gibi, âyinsiz dinî bir grup ahlâkî bir cemiyetin kurumu olur.

O hâlde ikinci bir ög€, yani âyinselin şeytanlaştırılmasına - onu ele avuca sığan ya da ele alınabilen bir obje kılmaya-karşı eleştirel bir hareket var. Bu öge çeşitli eleştirel tarzlarda tecessüm eder. Sözkonusu cleştirel hareketlerin ilki mistiktir. Bu mistik hareket, kişinin Nihaî'nin ya da Kutsal'ın herhangi somut ifadesi ile tatmin edilemediği anlamına gelir. Ve bu yüzden onların ötesine geçilir. İnsan, kesretin ötesindeki vahdete ulaşır. Nihaî olarak Kutsal, tecessümlerinin ötesinde uzanır. Tecessümler haklı çıkarılır. Onjar kabul edilır ancak ikincildir. Bizzat Nihâ̂'ye, en ulvîye ulaşmak için onların ötesine geçilir. Belirli, mahdut olan, Nihaî Bir adına inkar edilir, somutun değeri düşürülür.

Dinî tecrübedeki diğer yani üçüncü öge, "olması gereken" ögedir. Bu, etik ve peygamberî ögedir. Burada kutsallık adına adaletin inkarı gibi şeytanî sonuçlardan dolayı, âyinsel din tenkit edilir. Bu, âyinsel dine karşı Yahudi peygamberlerinin amansız mücadelesidir. Amos ve Hosea'nın sözlerinin bazılarında bu, bütün tapınma fesh edilene kadar devam ettirilir. Ayinsel temelin bu tenkidi Yahudilik için kesin olmanın yanı sıra, Hristiyanlıktaki ögelerden biridir. Fakat yine söyleyeceğim: Ayinsel ve mistik öge olmaksızın din, ahlâkî ve sonunda seküler olur.

"Somut Tin Dini" denilebilen -bu şekilde ifade etmede tereddütlüyüm ancak daha iyi bir söz aklımı gelmiyor- bir dindcki böyle üç ögenin birliğini tasvir etme arzusundayım. Ona, bir şeyin iç amacı anlamına gelen iç telos demek iyi olabilir; bir meşe palamudunun telosunun bir ağaç olmak olduğu gibi, dinler tarihinin iç amacı bir Somut Tin Dini olmaktır. Ancak biz Somut Tin Dinini, aktüel din ile, hatta din olarak Hristiyanlıkla bile 
özdeşleştiremeyiz. Elbette bir Protestan teoloğun cesareti olarak, ben inanıyorum ki, bu üç ögenin sentezi diyebileceğim şey için Paul'ün Tin Doktrin'inden daha iyisi yoktur. Orada biz vecdî ve rasyonel ögenin birliği anlamında iki ögeye sahibiz. Vecd vardır ancak vecdin en yüksek yaratımı, agape anlamındaki sevgidir. Vecd vardır fakat vecdin öteki yaratımı gnosis'tir yani Tanrı'nın bilgisi. O, bilgidir; karışıklık ve kaos değildir.

$\mathrm{Bu}$ ögelerin ya da motiflerin pozitif ve negatif ilişkisi dinler tarihinin dinamik karakterini verir. Benim bahsettiğim Somut Tin Dininin, iç telos'u, tâbir caizse her şeyi harekete geçiren şeydir. Ancak bunun sadece futuristik -yani aşırı derecede gelecekçi- bir beklenti olduğunu söyleyemeyiz. O, âyinsel temelin şeytanî direnmelerini ve âyinsel temelin eleştirmenlerinin şeytanî ve sekülerist tahriflerini hedef alan mücadelenin olduğu her şeyde ortaya çıkar. O, dinler tarihinin pek çok ânında peyder pey zuhur eder. Bu nedenle dinlerin geçmiş tarihini zapt etmeliyiz ve bu şekilde onu imha etmeliyiz; ancak bu büyük sentezin -peyder pey- gerçekleştiği anları içeren gerçek, yaşayan bir geleneğe sahibiz. Bütün dinler tarihini, bu anlamda din içindeki dine karşı Tanrı'nın bir mücadelesi, Somut Tin Dininin lehine bir mücadele olarak görebiliriz. Dine karşı din içindeki Tanrı'nın mücadelesi ibaresi, aksi hâlde son derece kaotik ya da en azından görünüşte kaotik dinler tarihini anlamak için anahtar olabilir.

Şimdi biz Hristiyanlar, bu mücadelede kesin zaferi İsa'nın Mesih olarak ortaya çıkmasında görürüz. Mesih için eski bir sembol vardır: Muzaffer Mesih (Christus Victor); ve bu, dinler tarihine ilişkin bu görüşte yine kullanılabilir. Böylece şeytanî güçler ve astrolojik güçler üstündeki zaferle Yeni Ahid'in bağlantısı sağlanmış olacaktır. O, her hangi bir şeytanî iddianın bir olumsuzlaması olarak haç üstündeki zafere işaret eder. Bunun, bize, Kristolojik dogma tartışmasının, başlangıçtan beri Hristiyan kiliselerini pek çok çıkmaza girmesinden kurtarabilen Kristolojik bir yaklaşım verebildiğini açıkça burada gördüğüme inanıyorum. Bu şekilde tarihteki eleştirel anların, Somut Tin Dininin aktüellik kazanmasındaki kairoi'lerin devamı şurada ya da burada peyder pey vuku bulabilir.

Hıristiyanlar olarak bizim için kriter çarmıh olayıdır. Sembolik bir şekilde orada vuku bulmuş olan -kriteri veren- şey (başka yerlerde ve başka zamanlarda da peyder pey vuku bulan) tarihsel ve tecrübî olarak çarmıhla ilgili olmasa bile, vuku bulmuştur ve vuku bulacaktır.

Simdi konferansin kesinlikle kalbi olan bir soruya geldik, yani dinler tarihinin bu gibi dinamikleri, dinî olan ve seküler olan arasındaki ilişkiyle nasıl bağlantılandırılacağ şeytanîleşmeye ve dinin şeytanî içerimlerine karşı bir mücadele olarak dine karşı Tanrı'nın mücadelesine açık değildir; kutsal, aynı zamanda sekülerleşmeye de açıktır. Ve sekülerleşme, şeytanîleşme karşıtının (dedemonization) üçüncü ve en radikal formu olduğu sürece, bunun ikisi yani şeytanîleşme ve sekülerleşme birbiriyle ilgilidir. Evet, bu fevkalade sistematik bir düşüncedir. 
Profan teriminin, "mäbedin kapısının önünde olma" ve seküler kavramının ise "dünyaya ait olma" anlamına geldiğini biliyorsunuz. Her iki durumda da, Kutsalın vecdî, gizemli korkusu sıradan rasyonel yapıların dünyası adına terk edilir. Eğer sekülere bizzat kendisi tarafından eleştirel dinî işlev verilmemişse, inșanları mabette tutmak için bununla mücadele etmek kolay olabilir. Ve bu problemi oldukça çetinleştirir. Seküler rasyoneldir ve rasyonelin Kutsalın irrasyonelliğini yargılaması gerekir. O, onun şeytanîleşmişliğini yarg̣ılamalıdır.

Hakkında konuşuyor olduğum rasyonel yapı ahlâkî, yasal, bilişsel ve estetik alanı imâ eder. Kutsalın verdiği hayatın takdisi aynı zamanda Kutsalın vecdî formları ile hayatın egemenliğidir ve de iyiliğin, adaletin, hakikatin ve güzelliğin aślî taleplerinin bastırılmasıdır. Bu bağlamda sekülerleşmenin oluşması özg̨ürlüktür.

$\mathrm{Bu}$ anlamda hem peygamberler hem de mistikler sekülerin atalarıdır. Kutsal yavaş yavaş ahlâkî olarak iyi ya da felsefî olarak doğru ve daha sonra da bilimsel olarak doğru, ya da estetik açıdan etkileyici hâle geldi. Ancak o zaman derin bir diyalektik ortaya çıktı. Seküler, yaşamak için bizatihi kendinin kaçınılmazlığını gösterir. Kutsalın egemenliğine karşı mücadele etmede haklı olan seküler anlamsız ve benim "sözde-dinler" dediğim şeyin kurbanı olur. Ve böyle "sözde-dinler", dinlerin şeytanî ögeleri gibi bir gaddarlığı imâ eder. Onlar, yüzyılımızda görmüş olduğumuz gibi, gerçek dinlerin derinlik ve zenginliğine sahip olmadığı için daha kötüdürler.

Burada diğer telos, yani dinler tarihinin iç amacı ortaya çıkar. Ben onu theos (Tanrı) ve nomos (ya:sa)'dan gelen teonomi ile isimlendiriyorum. Eğer bilginin, estetiğin, yasanın ve ahlâkın otonom güçleri hayatın nihaî anlamına işaret ederse, o hâlde biz teonomiyle karşı karşıyayız demektir. $O$ hâlde onlar dominant değildirler; ancak kendi içselliklerinde, bizzat kendilerinin ötesindeki Nihaîye işaret ederler. Gerçekte orada, heteronomi anlamına gelen hayatın kutsanması ile kültürel işlevlerin bütününün kendi kendine aktuielleşmesi -otonom ve anlamsız olan- arasında bir başka dinamik mücadele meydana gelir.

Teonomi benim Somut Tin Dini dediğim şeyde kesinlikle tam olarak değil de, peyder pey ortaya çıkar. Onun nâiliyeti eskatolojiktir; gayesi zamanın ötesine geçen beklentidir. Kutsal ve seküler ilişkisindeki bu teonom öge, Somut Tin Dininin yaprısındaki bir ögedir. $O$, her eylemde olduğu gibi, kesinlikle terakki eder. Bir konferans vermek için bile bazı yönlerde bizzat gelişmeye temayül vardır ancak söz konusu temayül ilerlemeci (progressivistic) değildir -bir zamanlardaki geçici bir nâiliyeti hayal etmez. Ve pek çok hususta kendime oldukça yakın hissettiğim Teilhard de Chardin'den burada ayrı düşüyorum.

Gelelim, üçüncü ve son mütalaam olan, dinî fenomen ışığında teolojik geleneğin yorumuna. Müsaadenizle, Berlin Üniversitesi'nde tanışıklığımızın hayli eskilere dayandığı, siaygın bir meslektaşımdan, Adolph Harnack'tan bahsedeyim. $\mathrm{O}$, bir keresinde Hristiyanlığın, kendi tarihi içinde dinler 
tarihinin bütün ögelerini kucakladığını söylemişti. Bu, kısmen doğru bir mütalaaydı ancak o, buna sonuna kadar bağlı kalmadı. Eğer söylediği şey geçerli olursa, o, bu durumda bütün din tarihi ile Hristiyan kilise tarihi arasında daha müspet bir ilişkinin olması gerektiği gerçeğini gözden kaçırmıs oldu. Ve böylece o, kendi yapıcı teolojisini, bir tür burjuvavân, bireyci, ahlâk teolojisi ile sınırladı.

Artık bu noktada iki yıldır süren seminer ve birlikte yürüttügümüz işbirliği için arkadaşım profesör Eliade'a şükranlarımı ifade etmeye dönmek istiyorum. Ben bu seminerlerde, her bireysel doktrinel ifade ya da Hristiyanlığın ritüel ifadesinin, yeni bir anlam yoğunluğu kazandığını tecrübe ettim. Bir tür apoloji yüzünden kendi kendini suçlama olsa da, Systematic Theology'imin böyle seminerlerden önce yazıldığını ve onun başka bir niyetinin yani, sekülere karşı ve sekülerle birlikte apolojik tartışma maksadının olduğunu kesinlikle söylemeliyim. Onun amacı Hristiyanlığa felsefî ve bilimsel tenkitlerinden gelen soruları tartı̧̧maktı ya da cevaplamaktı. Belki de bizim sistematik teolojik incelemenin ve dinsel tarihî incelemelerin daha uzun, daha yoğun bir yorumuna ihtiyacımız vardır. Böyle şartlar altında dinî düşüncenin yapısı, teonominin ya da Somut Tin Dininin diğer ya da farklı parça parça tezahürleri ile bağlantılı olarak gelişebilir. Teolojinin geleceği adına umudumdur, bu.

Söz konusu olasılığı görmek için sistematik teologa dinler tarihinin metodunu veren münhasır, belirli teoloji üstündeki vurgu örneğine bakmalıyız. Bu, doğaüstücü ve doğal teolojiye karşıtlık ફ̧eklindeki iki yadsıma çerçevesinde görülecektir. İlki, sistematik teoloji içinde Tanrı fikrinin klasik Protestan ortadoksluk tarzında formüle edildiği doğaüstücü teolojide görülebilir. Bu Tanrı kavramı, tarihte hazırlanmaksızın ilham edilen vahyî dökümanlarda ortaya çıkar. Ortodoksluk için bu görüşler Kitabı Mukaddeslerde, İslâm için ise Kur'an'da bulunabilir. Doktrinel mücadelelerle bağıntılı olarak, Kilise tarafından kutsal kitapların materyalleri arasından, genellikle akidelerin ya da doktrinlerin resmî koleksiyonunda düzenlenen ve felsefenin yardımıyla teolojik olarak açıklanan dogmatik ifadeler hazırlanır. Bütün bunlar kişinin kendi dini ya da imanı denilen vahiysel dairenin ötesine bakılmaksızın yapılır. Bu, bütün Hıristiyan kiliselerinde hâkim metottur.

Bir de, dinî kavramların, bir bütün olarak karşılaşılan gerçekliğin analizinden -özellikle de insan zihninin bir analizinden- felsefî olarak çıkarıldığı doğal teoloji metodu vardır. Genellikle Tanrı ve diğer kavramlar bundan sonra geleneksel doktrinlerle ilişkilendirilir; bazen de ilişkilendirilmez.

Bunlar geleneksel olarak kullanılan iki asıl metottur. Dinler tarihinin metodu aşağıdaki adımları takip eder: İlki, o, teolojik sahasında çalışanlarca, varoluşsal biçimde tecrübe edilen geleneğin materyalini kullanır. Teolojik olarak çalışılmaya başlanmasından itibaren dinler tarihçisi, herhangi bir gerçekliği gözlemek için gerekli olan tarafsızlığı da hâiz olmalıdır. Bu, ilk adımdır. 
İkinci adımda, dinler tarihçisi, hem bizzat kendimizde hem de bizim dışımızdaki dünyadaki insanî tecrübelerde tayin edilen dinî soruların yerini göstermek için, zihin ve gerçeklik analizini naturalist metodolojiden alır. Örneğin sonluluk tecrübesi, varlığımızın anlamına dâir ilgi tecrübesi, Kutsal olarak Kutsal tecrübesi, v.b. zikredilebilir.

Üçüncü adım, özellikle kendini dinler tarihinde açığa vuran, semboller, ritüeller, idealar ve çeşitli aktiviteler gibi fenomenleri sergileyen bir din fenomenolojisini sunar. Dördüncü adım, böyle fenomenlerle geleneksel kavramların ilişkisine ve bundan kaynaklanan yani onların birbiriyle ilişkileri, farklılıkları, çeliş̧ileri gibi problemlere işaret eden teşebbüsü barındırır. Son olarak dinler tarihçisi yeniden yorumlanan kavramları, dinî ve seküler tarihin dinamiklerinin çerçevesi içine ve özellikle de hâli hazırdaki dinî ve kültürel durumuzun yapısı içine yerleştirmeye çalışır. Şimdi bu beş adım daha önceki metotları kısmen içerir ancak bunlar, dinî tarihin büyük sembolleri içinde ifade edildiği gibi. insan ırkının tarihi bağlamında ve insanoğlunun tecrübesi içinde daha önceki metotlarca icra edilen şeyi ortaya koyar.

Her şeyi mevcut duruma yerleştiren son husus, yeni bir avantaja ya da -başka türlü söylemek gerckirse- yeni bir hakikat ögesine götürür. Bu, dinî sembollerin, içinde geliştiği ve onları bugüne yeniden takdim etmemiz gereken sosyal yapı ile ilişkisini anlama olasılığını sağlar. $\mathrm{Bu}$, son derece önemli bir adımdır. Dinî semboller gökten yağan taşlar değildir. Onların, yerel çevre dâhil insan tecrübesinin tamamında, hem politik hem de ekonomik bütün dallanıp budaklanmalarda köklerinin olduğu su götürmez bir gerçektir. Bu takdirde, böyle semboller onlara karşı başkaldırı olarak anlaşılabilir. Her iki durumda da bu, bizim sembolleri kullanma ve yeniden takdim etme tarzımız için önemlidir.

Bu metodun ikinci olumlu sonucu: Dinî sembolizmi, insan doktrinin yani antropolojinin -bu kelime emprik anlamda olmayıp, esas doğası içinde insan doktrini anlaminda - bir dili olarak kullanabiliriz. Dinî semboller bize asıl doğası içinde insanlarm kendilerini anlama tarzları hakkında bir şey söylerler. Hristiyanlık'da günah üstüne yapılan vurgu ve İslâm'da böyle bir vurgunun olmayışı iyi bir örnektir. Bu iki büyük din ve kültürün, insan olarak insanı yorumlamadaki temel farklılıklarını gösterir. Ve bu şekilde, bir bakıma belirli teknik bir psikolojiden daha kucaklayıcı olan insanın doğasına dâir anlayışımızı genişleteb liriz.

Gelelim son söze: Teoloğu olunan dinle ilişkimizde bu ne anlama gelir? Böyle bir teoloji, kendi tecrübî temellerinde kök salmış olarak kalır. Bu olmaksızın hiçbir teoloji kesinlikle mümkün değildir. Ancak o, evrensel olarak geçerli olan temel tecrübeleri, evrensel bakımdan geçerli olan ifadelerle formüle etmeye çalışır. Dinî bir ifadenin evrenselliği, aslında dini parçalayan her şeyi kucaklayıcı bir soyutlamada yatmaz fakat o, her somut dinin derinliklerinde uzanır. Dahası o, hem kişinin kendi temelinden hem de onun kendi temeli için tinsel özgürlüğe açıklığında yatar. 